\title{
A Role for $\alpha 1$ Tubulin-Expressing Müller Glia in Regeneration of the Injured Zebrafish Retina
}

\author{
Blake V. Fausett and Daniel Goldman \\ The Molecular and Behavioral Neuroscience Institute and Department of Biological Chemistry, University of Michigan, Ann Arbor, Michigan 48109
}

$\alpha 1$ tubulin $(\alpha 1 \mathrm{~T})$ is a neuron-specific microtubule protein whose expression is induced in the developing and regenerating CNS. In the adult CNS, $\alpha 1 \mathrm{~T}$ expression remains high in neural progenitors. Transgenic zebrafish harboring a $1.7 \mathrm{~kb} \alpha 1 \mathrm{~T}$ promoter fragment along with the first exon and intron express the transgene in a manner that recapitulates expression of the endogenous gene. We recently showed that this promoter mediates gene induction in retinal ganglion cells during optic nerve regeneration and in a subset of Müller glia that proliferate after retinal injury (Senut et al., 2004). To further characterize these Müller glia, we generated transgenic fish harboring an $\alpha 1 \mathrm{~T}$ promoter fragment that is specifically induced in these cells after retinal damage. Transgene expression, bromodeoxyuridine (BrdU) labeling, and stem cell marker expression suggested that $\alpha 1 \mathrm{~T}$-expressing Müller glia dedifferentiate and become multipotent in response to injury. In addition, green fluorescent protein and BrdU-mediated lineage tracing combined with retinal gene expression analysis indicated that $\alpha 1 \mathrm{~T}$-expressing Müller glia were capable of generating retinal neurons and glia. These data strongly suggest $\alpha 1 \mathrm{~T}$-expressing Müller glia dedifferentiate and mediate regeneration of the injured zebrafish retina.

Key words: Müller glia; stem cells; regeneration; retina; zebrafish; tubulin

\section{Introduction}

The capacity of fish to regenerate an injured retina has been recognized for decades (for review, see Hitchcock et al., 2004). Mechanical, chemical, or light-induced retinal lesions have been shown to stimulate a regenerative response that is capable of restoring retinal architecture and function (Maier and Wolburg, 1979; Hitchcock et al., 1992; Braisted et al., 1994; Cameron, 2000; Vihtelic and Hyde, 2000). Interestingly, retinal injury produces columns of proliferating cells known as "neurogenic clusters." These neurogenic clusters express markers of retinal stem cells such as Pax6 (paired box gene 6), Vsx1 (visual system homeobox 1 homolog), Notch-3, and N-cadherin (Levine et al., 1994; Hitchcock et al., 1996; Sullivan et al., 1997; Wu et al., 2001). It was originally speculated that these clusters were derived from rod precursors (Raymond et al., 1988). However, with the identification of putative stem cells in the inner nuclear layer (INL) of the goldfish retina (Otteson et al., 2001) and evidence that INL cell proliferation precedes retina regeneration (Braisted et al., 1994; Vihtelic and Hyde, 2000; Wu et al., 2001; Yurco and Cameron, 2005), it seems likely that putative stem cells in the INL are the

Received Sept. 23, 2005; revised April 25, 2006; accepted May 6, 2006.

This work was supported by Michigan Life Sciences Corridor Research Grant MEDC-38 (D.G.) and a National Institutes of Health vision research training grant (B.V.F.). We thank the Microscopy and Image Analysis Laboratory (University of Michigan) for help with electron microscopy and members of the Goldman laboratory for comments and suggestions on this work and manuscript.

Correspondence should be addressed to Daniel Goldman, University of Michigan, Molecular and Behavioral Neuroscience Institute, Biomedical Sciences Research Building, 109 Zina Pitcher Place, Ann Arbor, MI 48109. E-mail: neuroman@umich.edu.

DOI:10.1523/JNEUROSCI.0332-06.2006

Copyright $\odot 2006$ Society for Neuroscience $\quad$ 0270-6474/06/266303-11\$15.00/0 predominant source of progenitors for retinal regeneration. Interestingly, Müller glia, whose cell bodies are also located in the INL, show a proliferative response after retinal injury and have not been eliminated as a source of retinal progenitors (Braisted et al., 1994; Wu et al., 2001). In addition, Müller glia have been suggested as a source of retina regeneration in zebrafish (Yurco and Cameron, 2005). Recent reports that Müller glia in postnatal chicks (Fischer and Reh, 2001) and rodents (Ooto et al., 2004) have a limited capacity to generate neurons after retinal injury further implicates them as a potential source of retina repair in the damaged fish retina. However, the lack of suitable markers for retinal stem cells and the inability to perform lineage tracing in adult fish make the identification of the cellular source of retina regeneration difficult.

We previously demonstrated that a $1.7 \mathrm{~kb} \alpha 1$ tubulin $(\alpha 1 \mathrm{~T})$ promoter fragment along with its first exon and intron directed green fluorescent protein (GFP) transgene expression to the developing and regenerating zebrafish CNS (Goldman and Ding, 2000; Goldman et al., 2001; Senut et al., 2004). In the adult CNS, this promoter directs transgene expression to neural progenitors (Goldman et al., 2001). Interestingly, retinal injury causes induction of the $\alpha 1 \mathrm{~T}$ promoter in a subpopulation of Müller glia that are proliferative (Senut et al., 2004; Vihtelic et al., 2006) and exhibit certain characteristics that are shared with stem cells (Yurco and Cameron, 2005). In light of these observations and because Müller glia have been reported to generate retinal neurons in other systems (Fischer and Reh, 2001; Ooto et al., 2004), we were interested in determining whether the $\alpha 1 \mathrm{~T}$-expressing Müller glia function as neural progenitors in the injured zebrafish retina. Here we report that $\alpha 1 \mathrm{~T}$-expressing Müller glia are able to 
dedifferentiate, proliferate, and generate new neurons to repair the damaged retina.

\section{Materials and Methods}

Animals. The animals used in this study were treated in accordance with the guidelines of the University Committee on Use and Care of Animals at the University of Michigan. A total of 31 adult zebrafish (Danio rerio) were used in this study. They were obtained from our breeding colony and raised with a $14 / 10 \mathrm{~h}$ light/dark cycle at a temperature of $28^{\circ} \mathrm{C}$.

Generation of transgenic zebrafish. 1016 $\alpha 1$ TIPEGFP expression vector contains 1016 bp of $5^{\prime}$ flanking $\alpha 1$-tubulin DNA, exon 1, and the first intron fused in-frame to the GFP sequence. This promoter fragment is similar to the full-length $1696 \alpha 1$ TIpEGFP expression vector from previous work (Goldman and Ding, 2000; Goldman et al., 2001; Senut et al., 2004), except that it is lacking $680 \mathrm{bp}$ from the $5^{\prime}$ end. $1016 \alpha 1$ TIpEGFP DNA was resuspended in injection buffer, and single-cell zebrafish embryos were injected as described previously (Goldman and Ding, 2000). Injected fish were bred and screened for reporter gene expression (Goldman and Ding, 2000; Goldman et al., 2001).

Optic nerve lesions. Fish were anesthetized in $0.02 \%$ tricaine methane sulfonate (Sigma, St. Louis, MO) before surgery. Optic nerve crushes were performed as described previously (Hieber et al., 1998). Under microscopic visualization, the right eye was gently pulled from its socket, and the exposed optic nerve was crushed behind the eyeball using watchmaker's forceps. Care was taken not to lesion the ophthalmic artery running along the optic nerve. The left optic nerve was kept intact, its retina serving as an unoperated control. After surgery, fish were returned to their tanks for $4 \mathrm{~d}$.

Eye lesions. Eye lesions were performed as described previously (Senut et al., 2004). Briefly, fish were anesthetized, and, under microscopic visualization, the right eye was gently pulled from its socket and stabbed four times (once in each quadrant) through the sclera with a 30 gauge needle. The needle was inserted to the length of the bevel $(\sim 5 \mathrm{~mm})$ to achieve similar lesions from case to case. The left eye served as an unoperated control. After surgery, fish were returned to their tanks to recover.

Bromodeoxyuridine injections. To identify dividing cells, bromodeoxyuridine (BrdU) injections were performed as described previously (Byrd and Brunjes, 2001) with minor modifications. Briefly, after anesthesia in $0.02 \%$ tricaine methane sulfonate, fish in which the retina had been punctured earlier received a single intraperitoneal injection of $20 \mu \mathrm{l}$ of a $25 \mathrm{mg} / \mathrm{ml} \mathrm{BrdU} \mathrm{(Sigma)} \mathrm{stock} \mathrm{solution.} \mathrm{Fish} \mathrm{were} \mathrm{killed} \mathrm{at} \mathrm{various}$ times after BrdU injection.

Tissue preparation. Fish were given an overdose of tricaine methane sulfonate, and eyes from adult fish were dissected, enucleated, and fixed by immersion in fresh $1 \%$ (to preserve GFP fluorescence) or $4 \%$ paraformaldehyde in $0.1 \mathrm{~m}$ phosphate buffer (PB), $\mathrm{pH} 7.4$, for $16 \mathrm{~h}$. After fixation, samples were cryoprotected in phosphate-buffered $20 \%$ sucrose before embedding with O.C.T. mounting medium (Sakura Finetek, Torrance, CA). Embedded samples were kept at $-70^{\circ} \mathrm{C}$ until sectioning. Six to eight micrometer serial sections were obtained on a cryostat (CM3050S; Leica, Nussloch, Germany), collected on Superfrost/Plus slides (Fisher Scientific, Pittsburgh, PA), dried overnight at room temperature, and stored at $-70^{\circ} \mathrm{C}$.

Immunohistochemistry. Immunohistochemistry was performed as described previously (Senut et al., 2004) using the following primary antibodies: rat anti-BrdU (dividing cell marker; 1:250; Harlan Sera-Lab, Loughborough, UK); mouse zpr1 [double-cone photoreceptor marker (Larison and Bremiller, 1990); 1:250; Zebrafish International Resource Center (ZIRC), Eugene, OR]; rabbit anti-GFP (1:1000; Invitrogen, Carlsbad, CA); mouse anti-HuC/D (amacrine cell marker; 1:500; Invitrogen); rabbit anti-protein kinase C (PKC) [ON bipolar cell marker (Yazulla and Studholme, 2001); 1:250; Santa Cruz Biotechnology, Santa Cruz, CA]; mouse anti-tyrosine hydroxylase (TH) (interplexiform cell marker; 1:500; Chemicon, Temecula, CA); mouse anti-zrf1 (glial marker; 1:250; ZIRC); mouse anti-zn5 [retinal ganglion cell (RGC) marker; 1:500; ZIRC]; and mouse anti-glutamine synthetase (GS) (glial marker; 1:500; Chemicon). For BrdU immunostaining, sections were pretreated with $2 \mathrm{~N} \mathrm{HCl}$ for $30 \mathrm{~min}$ at $37^{\circ} \mathrm{C}$, two $5 \mathrm{~min}$ rinses in $0.1 \mathrm{M}$ sodium borate buffer, and three 5 min rinses in PBS, pH 7.4. Primary antibodies were diluted in PBS containing 1\% donkey serum and 0.3\% Triton X-100 [normal donkey serum/Triton (NDST) 1\%]. Cryostat sections were first rehydrated $10 \mathrm{~min}$ in PBS, preincubated in NDST 3\% for $30 \mathrm{~min}$ at room temperature, and then incubated in the primary antibodies overnight at $4^{\circ} \mathrm{C}$. Sections were rinsed three times in NDST $1 \%$ and incubated for $2-3$ $\mathrm{h}$ at room temperature with secondary anti-mouse, anti-rabbit, or antirat antibodies conjugated to Alexa 488 (1:1000; Invitrogen) or cyanine 3 (1:250; Jackson ImmunoResearch, West Grove, PA). Sections were then washed twice in PBS, once in $\mathrm{PB}$, and then with water containing 10 $\mathrm{ng} / \mathrm{ml}$ 4,6-diamidino-2-phenylindole (DAPI) (Sigma) for nuclear staining. Slides were washed twice with water and allowed to dry in the dark. Slides were then coverslipped using MOWIOL and subsequently stored in the dark at $4^{\circ} \mathrm{C}$.

In situ hybridization. In situ hybridizations were performed with digoxigenin-labeled cRNA probes as described previously (Barthel and Raymond, 2000). Pax6 cRNA was prepared from a full-length Pax6a cDNA clone (Open Biosystems, Huntsville, AL) linearized by EcoRV digestion, followed by transcription with T7 RNA polymerase. A sense control probe was made and produced no signal.

Imaging. Slides were examined using a Zeiss (Oberkochen, Germany) Axiophot or LSM510 confocal microscope. Images were captured using a digital camera adapted onto the Axiophot microscope or with a Zeiss LSM510 confocal microscope. Images were processed and annotated with Adobe Photoshop CS (Adobe Systems, San Jose, CA).

Transmission electron microscopy. Enucleated eyes from 4-5 d postinjury (dpi) $1016 \alpha 1 \mathrm{~T}$ transgenic fish were fixed in $2.5 \%$ glutaraldehyde and $3 \%$ paraformaldehyde in $0.1 \mathrm{~m}$ Sorensen's buffer, $\mathrm{pH} 7.4$, for $4 \mathrm{~h}$. After several buffer rinses, eyes were postfixed in $1 \%$ osmium tetroxide in the same buffer, rinsed in $\mathrm{ddH}_{2} \mathrm{O}$ to remove phosphate, and then en bloc stained with aqueous $3 \%$ uranyl acetate for $1 \mathrm{~h}$. Eyes were then dehydrated in ascending concentrations of ethanol, treated with propylene oxide, and embedded in Epon epoxy resin. Semithin sections were obtained and stained with toluidine blue to identify lesions. Ultrathin sections $(70 \mathrm{~nm})$ were then taken for selected regions of interest, stained with uranyl acetate and lead citrate, and examined using a Philips (Aachen, Germany) CM100 electron microscope at $60 \mathrm{kV}$. Digital images were recorded with a Hamamatsu (Bridgewater, NJ) ORCA-HR digital camera system operated with AMT software (Advanced Microscopy Techniques, Danvers, MA).

\section{Results}

\section{$1016 \alpha 1 \mathrm{~T}$ transgene expression is induced in Müller glia after retinal injury}

We previously reported that transgenic fish harboring the wildtype $1.7 \mathrm{~kb} \alpha 1 \mathrm{~T}$ promoter predominantly express GFP in proliferating Müller glia within 3 d of retinal injury (Senut et al., 2004). We hypothesized that $\alpha 1 \mathrm{~T}$-expressing Müller glia may function as retinal stem cells based on four observations. First, Müller glia exhibit proliferative properties and survival typical of stem cells (Yurco and Cameron, 2005). Second, the $\alpha 1 \mathrm{~T}$ transgene is predominantly expressed in stem cells of the adult CNS (Goldman et al., 2001), suggesting that its expression in the retina may identify stem cells there. Third, transgene-expressing Müller glia begin to express the neuronal marker $\mathrm{HuC} / \mathrm{D}$ at 1 week after light-induced retinal injury (Vihtelic et al., 2006), suggesting that cells derived from transgene-expressing Müller glia may differentiate into neurons. Fourth, Müller glia in postnatal birds and rodents can be induced to generate new neurons (Fischer and Reh, 2001; Ooto et al., 2004).

To pursue these studies, we thought it was important to identify an $\alpha 1 \mathrm{~T}$ promoter fragment that specifically directed transgene expression to Müller glia that proliferate after retinal injury. Because the $1.7 \mathrm{~kb}$ promoter fragment is induced in cells that are regenerating their damaged axons (Goldman et al., 2001; Senut et al., 2004), it is not a suitable promoter for these studies. Therefore, we assayed various promoter deletions in transgenic fish for 

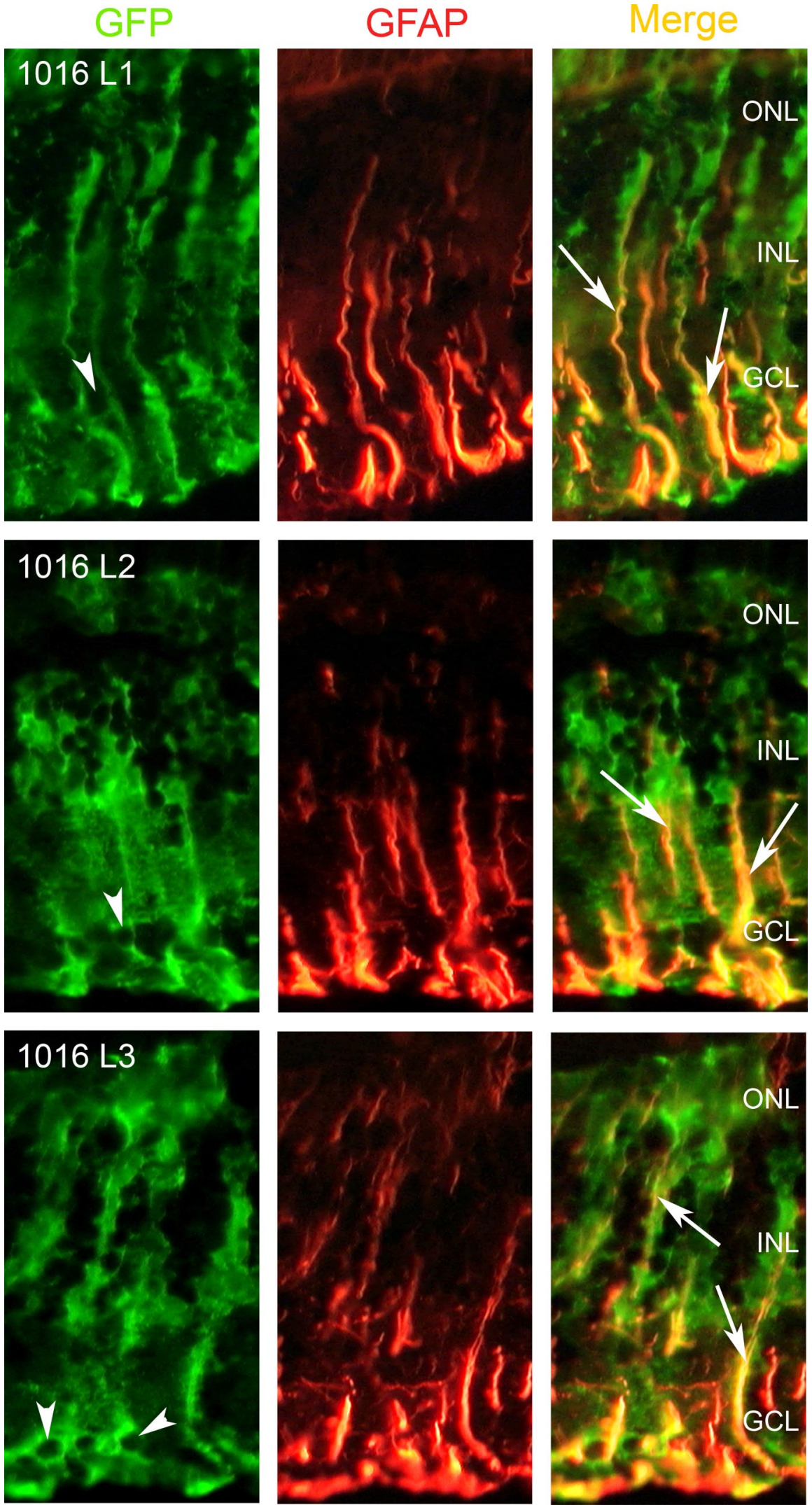

Figure 1. 1016 $\alpha 1$ T:GFP transgenic fish induce GFP expression in Müller glia after retinal injury. Three independent lines of transgenic fish $(1016 \mathrm{~L} 1,1016 \mathrm{~L} 2,1016 \mathrm{~L} 3)$ were tested for induction of GFP in the retina $4 \mathrm{~d}$ after retinal injury. The panels labeled GFP show transgene GFP expression in Müller-like cells. The middle panels show staining for GFAP, a Müller glial marker. The merged images (right panels) show that GFP-expressing cells also express GFAP (arrows). Retinal ganglion cells do not express GFP in response to injury (arrowheads). expression after retinal injury and identified deletion $1016 \alpha 1 \mathrm{~T}$ that is missing 680 bp from the $5^{\prime}$ end of the $\alpha 1 \mathrm{~T}$ promoter. Three independent lines of transgenic fish were identified that harbored the $1016 \alpha 1 \mathrm{~T}$ :GFP transgene in their germ line, and all exhibited expression in Müller glia after injury but not in injured retinal ganglion cells (Fig. 1). To confirm that 1016 $\alpha 1 \mathrm{~T}: \mathrm{GFP}$ transgene expression was not induced in injured retinal ganglion cells, we first performed in situ hybridizations on sections from 4 dpi retinas and found that the $1016 \alpha 1 \mathrm{~T}$ transgene was expressed in endogenous $\alpha 1$ tubulinexpressing cells of the INL but not in $\alpha 1$ tubulin-expressing retinal ganglion cells (data not shown). Next, we examined transgene expression after optic nerve crush. As expected, the injured ganglion cells expressed GAP43, which is induced during axon regeneration (Perry et al., 1987; Bormann et al., 1998), but not GFP (supplemental Fig. 1, available at www. jneurosci.org as supplemental material), confirming our initial observations that retinal ganglion cells harboring the $1016 \alpha 1 \mathrm{~T}$ :GFP transgene do not induce GFP in response to injury. In uninjured control retinas, endogenous $\alpha 1 \mathrm{~T}$ is only expressed in progenitors and differentiating progeny at the circumferential germinal zone (CGZ), and the $1016 \alpha 1 \mathrm{~T}$ transgene retains this expression pattern (supplemental Fig. 2, available at www.jneurosci.org as supplemental material).

\section{$1016 \alpha 1 T$-expressing Müller glia} proliferate after retinal injury

To more carefully examine cell proliferation after retinal injury and correlate this with transgene expression (see below), we performed a BrdU pulse-labeling experiment. $1016 \alpha 1 \mathrm{~T}$ :GFP transgenic fish received retinal lesions at day 0 (0 dpi) and were given a single dose of BrdU at $24 \mathrm{~h}$ intervals (1dpi, $2 \mathrm{dpi}$, etc.). The fish were then killed $4 \mathrm{~h}$ after BrdU administration, and the eyes were isolated, cryoprotected, and serially sectioned. BrdU-labeled $\left(\mathrm{BrdU}^{+}\right)$cells adjacent to the injury were quantified to estimate the total number of $\mathrm{BrdU}^{+}$cells per lesion (Fig. 2a). Previous studies had shown that there is no detectable cell proliferation outside the CGZ in the retinal margin of adult zebrafish at 0 and 1 dpi (Cameron, 2000; Yurco and Cameron, 2005). However by 2 dpi, cell proliferation in the outer nuclear layer (ONL) and INL is observed (Yurco and Cameron, 2005). Consistent with these results, at $1 \mathrm{dpi}$, we rarely observed $\mathrm{BrdU}^{+}$ cells in the extant retina, and those that 
were labeled were generally found in the ONL in which rod progenitors, described previously in goldfish, are found (Johns, 1977; Meyer, 1978) and in the optic fiber layer, in which proliferating microglia can be found (Negishi and Shinagawa, 1993; Braisted et al., 1994; Yurco and Cameron, 2005). BrdU ${ }^{+}$cells in the CGZ were observed at all time points, indicating that BrdU administration was successful at labeling proliferating cells (data not shown), but were excluded from our cell counts. At $2 \mathrm{dpi}$, there is a dramatic increase in the number of $\mathrm{BrdU}^{+}$cells in the INL, and $76 \%$ of the total $\mathrm{BrdU}^{+}$cell population resides in the INL ( 183 of $238 \mathrm{BrdU}^{+}$cells per lesion). Interestingly, this increase precedes the increased number of BrdU ${ }^{+}$cells in the ONL at $3 \mathrm{dpi}$, perhaps indicating that cells from the INL give rise to the proliferating cells observed at later time points. The number of $\mathrm{BrdU}^{+}$cells in the INL and ONL reached a peak at 4 dpi before declining and returning to near baseline levels by 7 dpi (Fig. $2 a$ ). These data suggest that the cells that are required to repopulate a damaged retina are rapidly produced in response to injury and is consistent with previous work demonstrating a spatiotemporal pattern of cell proliferation after injury (Yurco and Cameron, 2005).

We wondered what portion of the BrdU-labeled cells corresponded to GFP-expressing $\left(\mathrm{GFP}^{+}\right)$cells. To answer this question, we assayed $\mathrm{BrdU}^{+}$cells for GFP expression (Fig. 2b). At $1 \mathrm{dpi}$, rare $\mathrm{BrdU}^{+}$cells that could be rod progenitors and microglia could be identified based on their nuclear morphology and position within the retina (Fig. $2 c, d$ ). Although there were few BrdU ${ }^{+}$cells at 1 $\mathrm{dpi}$, some of these were also $\mathrm{GFP}^{+}$and probably represent the earliest expression of the transgene in activated Müller glia (Fig. $2 e-g$ ) (see below). Almost all $\mathrm{BrdU}^{+}$cells in the INL at $2-5 \mathrm{dpi}$ are also GFP ${ }^{+}$(Fig. $2 b$ ) and have typical Müller glia morphology (Fig. $2 h-k$ ). At 3 dpi and later, we noticed some $\mathrm{GFP}^{+}$Müller cells that were not labeled with BrdU (Fig. 2j, arrowhead). The $\mathrm{BrdU}^{-} / \mathrm{GFP}^{+}$cells are always associated with elongated nuclear morphology that is typical of the $\mathrm{BrdU}^{+}$nuclei, and we expect that these cells are also proliferative but were not in S-phase at the time of BrdU administration (see below). From 6-7 dpi, GFP expression declines and corresponds to reduced BrdU labeling at these time points. These data indicate that proliferating cells also express GFP during the first week after retinal injury.

Although most BrdU ${ }^{+}$cells express GFP at 4 dpi $(94 \%$ of the total $\mathrm{BrdU}^{+}$cells, 1087 of 1161 ; and $98 \%$ of the $\mathrm{INL} \mathrm{BrdU}^{+}$cells, 662 of 673) and these $\mathrm{GFP}^{+}$cells appeared to be Müller glia based on cell morphology, we wanted to determine whether the $1016 \alpha 1 \mathrm{~T}$ promoter drives transgene expression exclusively in Müller glia after injury. We therefore examined whether two Müller glial markers, zrf1 [which recognizes glial fibrillary acidic INL; $\mathbf{\Delta}, \mathrm{GCL}$.
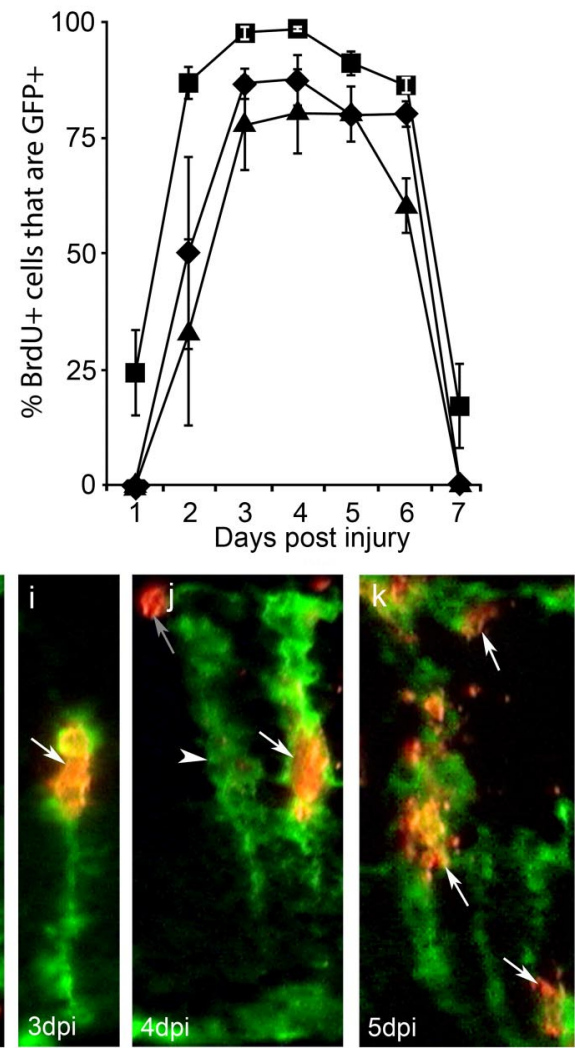

5 dpi

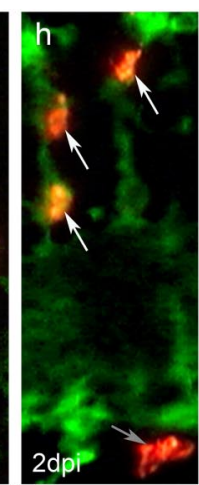

Figure 2. Injury-induced cell proliferation and GFP expression. $\boldsymbol{a}$, Graph showing the average number of BrdU ${ }^{+}$cells per lesion percentage of $\mathrm{BrdU}^{+}$cells quantified in a that are also GFP ${ }^{+}$at each day after injury $\mathbf{c}_{-} \boldsymbol{k}_{\text {I }}$ Images of $\mathrm{Brdu}^{+} / \mathrm{GFP}^{+}$cells from $2-5$ dpi. $\boldsymbol{c}, \boldsymbol{d}$, At 1 dpi, few cells were BrdU ${ }^{+}$, although rare cells considered to be rod progenitors (c) and microglia $(\boldsymbol{d})$ based on

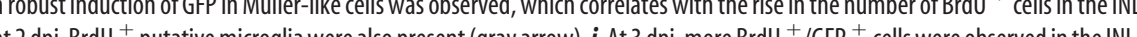
$\mathrm{BrdU}^{+}$cells in the INL is decreasing, but GFP ${ }^{+}$proliferative cells can be identified in all three nuclear layers (arrows).

protein (GFAP)] and GS, colocalized with GFP expression at 4 dpi. Confocal microscopy showed that $\mathrm{GFP}^{+}$cells also express Müller glial markers (Fig. 3). We next quantified the coexpression of GFP and glial markers to determine what percentage of the $\mathrm{GFP}^{+}$cells could be considered Müller glia. Of $107 \mathrm{GFP}^{+}$ cells assayed for GFAP expression, 105 (98\%) were labeled. Of $205 \mathrm{GFP}^{+}$cells assayed for GS expression, 200 (98\%) were labeled. We also performed immunostaining with the neuronal marker HuC/D and other retinal cell-type specific markers (zpr1, $\mathrm{PKC}$, and TH; data not shown) to determine whether any other retinal cell types expressed GFP at 4 dpi. Despite an extensive search, no colabeling could be identified. Although we cannot rule out the possibility that a small cell population in the INL other than Müller glia proliferates in response to injury, our data suggest that such a population represents $<2 \%$ of the total proliferating INL cell population.

\section{Neurogenic clusters are derived from proliferating Müller glia}

We noticed that $\mathrm{GFP}^{+}$cells are remarkably similar to neurogenic clusters of regenerating cells described by others studying retina 

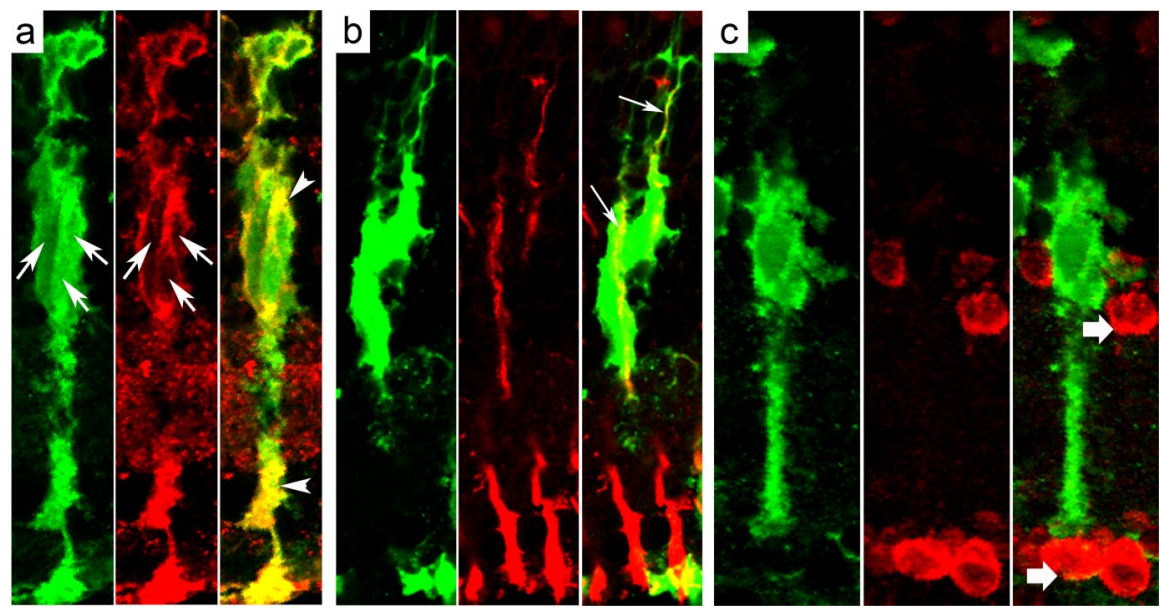

Figure 3. 1016 $\alpha 1 \mathrm{~T}: G F P$ expression is specific to Müller glia. Sections from 1016 transgenic $4 \mathrm{~d}$ postinjured retinas were examined by confocal microscopy to determine whether GFP expression was induced specifically in Müller glia. Cells were assayed for colocalization of GFP (green panels) with the Müller glial markers GS (red in $\boldsymbol{a}$ ) and GFAP (red in $\boldsymbol{b}$ ) and the neuronal marker $\mathrm{HuC/D}$ (red in c). $\boldsymbol{a}$, GFP is expressed in Müller cells, which are labeled by GS immunostaining. There are three GFP ${ }^{+}$nuclei that appear as GS - holes in this micrograph (arrows). Note the coexpression of GFP and GS in the cytoplasm (arrowheads). 0f 205 $\mathrm{GFP}^{+}$cells assayed for GS expression, 200 (98\%) were double labeled. $\boldsymbol{b}$, GFP-positive cells also express GFAP (arrows). 0 f 107 $\mathrm{GFP}^{+}$cells assayed for GFAP expression, 105 (98\%) were double labeled. c, Amacrine cells labeled with the neuronal marker $\mathrm{HuC/D}$ do not express GFP after injury (wide arrows). Cells double labeled with HuC/D and GFP were never observed at $4 \mathrm{dpi}$.

regeneration in zebrafish and goldfish (Raymond et al., 1988; Vihtelic and Hyde, 2000; Faillace et al., 2002; Yurco and Cameron, 2005). The origin of these clusters has not been identified, but they are formed in response to injury and appear as a group of cells with elongated nuclei that can be identified by BrdU labeling or by staining with antibodies to proliferating cell nuclear antigen. In the injured $1016 \alpha 1 \mathrm{~T}$ :GFP transgenic retina, groups of cells with elongated nuclei always correspond to $\mathrm{GFP}^{+}$Müller glia, leading us to hypothesize that the $\mathrm{GFP}^{+}$cells we observe are neurogenic clusters. In the injured goldfish retina, neurogenic clusters are known to express markers of stem/progenitor cells such as Pax6, Vsx1, Notch-3, and N-cadherin (Levine et al., 1994; Hitchcock et al., 1996; Sullivan et al., 1997; Wu et al., 2001). To determine whether $\mathrm{GFP}^{+}$Müller glia express markers of stem cells, we assayed for Pax6 expression in 4 dpi retinas from $1016 \alpha 1 \mathrm{~T}$ transgenic fish (Fig. 4). This stem cell marker was induced in the $\mathrm{GFP}^{+}$population of Müller glia (30 of $33 \mathrm{GFP}^{+}$
Fig. 3, available at www.jneurosci.org as supplemental material). BrdU-labeled cells were present in the ONL and ganglion cell layer (GCL) at all time points, suggesting that $\mathrm{BrdU}^{+}$cells from the INL had migrated to these layers or that the few $\mathrm{BrdU}^{+}$cells within the ONL and GCL had divided (supplemental Fig. 3, available at www.jneurosci.org as supplemental material)

\section{Neurogenic clusters are closely associated cells with characteristics of Müller glia}

We observed that each neurogenic cluster appeared to correspond to a single, hypertrophied, $\mathrm{GFP}^{+}$Müller glia. Confocal microscopy revealed that $\mathrm{BrdU}^{+}$nuclei reside within what appears to be a single $\mathrm{GFP}^{+}$Müller glia (Fig. 5). We captured stacks of images to produce orthogonal projections and found that $\mathrm{BrdU}^{+}$nuclei expressed GFP (Fig. $5 a$, top, arrows). Nuclei within what appears to be a single Müller glia express GFP (Fig. 5b, white
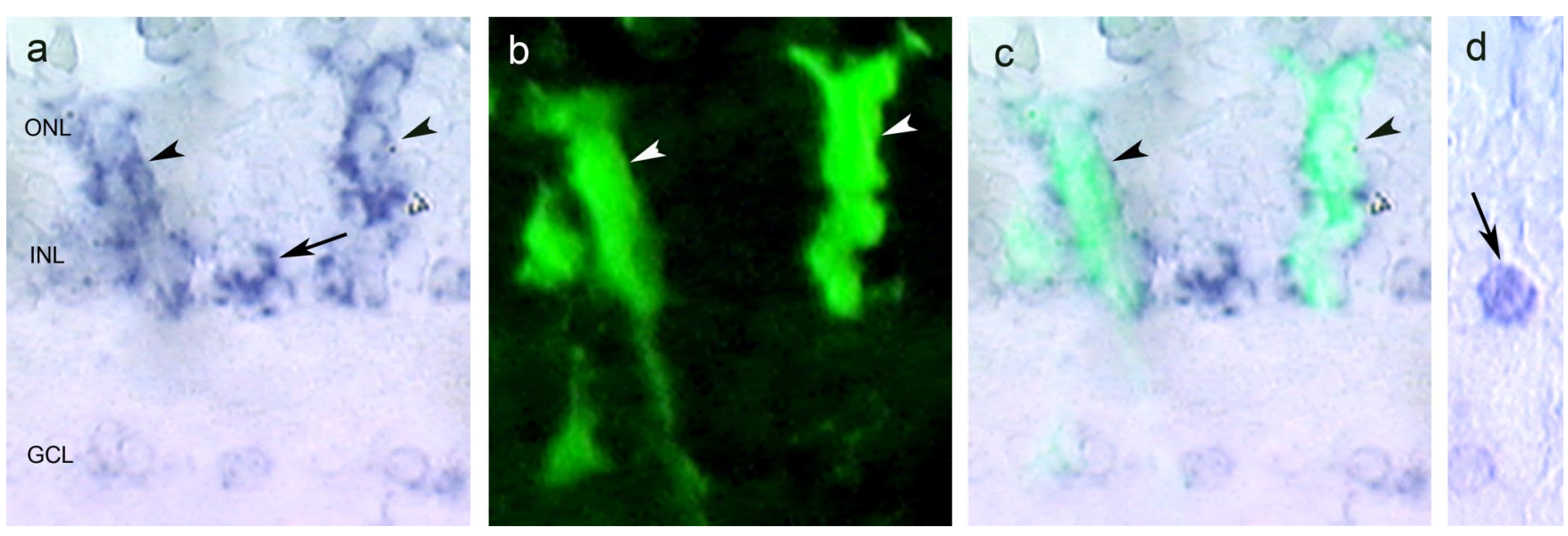

Figure 4. Neurogenic clusters are derived from Müller glia. Sections from 4 dpi retinas were processed for GFP expression (green), and then in situ hybridization for Pax6 mRNA (blue) was performed. $\boldsymbol{a}$, Pax6 is induced in columns of elongated cells known as neurogenic clusters in response to injury (arrowheads). Amacrine cells normally express Pax6 (arrow; see also $\boldsymbol{d}$ ). $\boldsymbol{b}$, GFP is expressed by Müller glia in response to injury (arrowheads). c, GFP ${ }^{+}$cells derived from Müller glia correspond to Pax6-expressing neurogenic clusters (arrowheads). $\boldsymbol{d}$, Pax6 is expressed in the uninjured retina in amacrine cells (arrow). 
arrows), whereas nuclei outside the GFP Müller glia do not (Fig. 5b, arrowhead). To determine whether the proliferating cells had undergone karyokinesis without cytokinesis or whether the cells were clusters of individual $\mathrm{GFP}^{+}$cells, we performed electron microscopy on sections from $4-5 \mathrm{dpi}$ retinas (data shown for 4 dpi in Fig. $5 c-f$ ). The elongated proliferating nuclei that are faintly stained with DAPI (Fig. $5 a, b$, insets) are always $\mathrm{GFP}^{+}$and can be easily identified in the light microscope based on these criteria. These neurogenic clusters are also identifiable in the electron microscope because of their distinct chromatin pattern and elongated nuclear morphology (Fig. $5 c$, asterisks). We examined several neurogenic clusters $(n=5)$ and found thin plasma membranes separating individual elongated nuclei (Fig. $5 d$, arrowheads), indicating that the clusters are composed of tightly associated cells. Additional analysis of the electron micrographs showed that cells within neurogenic clusters shared certain characteristics with Müller glia. First, the cytoplasm of neurogenic clusters is indistinguishable from that of the neighboring Müller glia whose processes are extending around them (Fig. 5e,f). Müller glia form stereotypical junctions with other Müller glia (Krebs and Krebs, 1991) that are readily identified in the electron microscope (Fig. $5 c, e, f)$. Second, we identified elongated nuclei in the inner plexiform layer (IPL) surrounded by cytoplasm that extended processes laterally (supplemental Fig. 4, available at www.jneurosci.org as supplemental material), which is typical of Müller glial processes in this layer (Krebs and Krebs, 1991). These data provide additional evidence to suggest that neurogenic clusters are derived from proliferating Müller glia.

\section{Müller glia give rise to new neurons after injury}

The above data suggest that $1016 \alpha 1 \mathrm{~T}$ expressing Müller glia respond to retinal injury by dedifferentiating and expressing retinal stem cell markers such as Pax6 and $\alpha 1$ T. If these cells function as injuryinduced retinal progenitors, they should ultimately generate new neurons. Ideally, we would use GFP expression as a lineage tracer to follow the fate of these cells. However, GFP expression is transient and becomes barely detectable after $14 \mathrm{dpi}$, suggesting that GFPexpressing cells have differentiated (data not shown). Therefore, we focused our attention on early time points (7-11 dpi) when new retinal neurons may be forming and GFP expression would be easily detected. We used two different markers for this experiment. First, we used $\mathrm{HuC} / \mathrm{D}$ expression to identify newly born neurons because some Müller glia express this marker $7 \mathrm{~d}$ after photoreceptor damage (Vihtelic et al., 2006). Next, we used zn5,

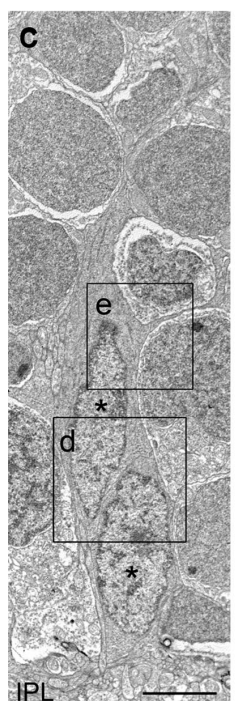

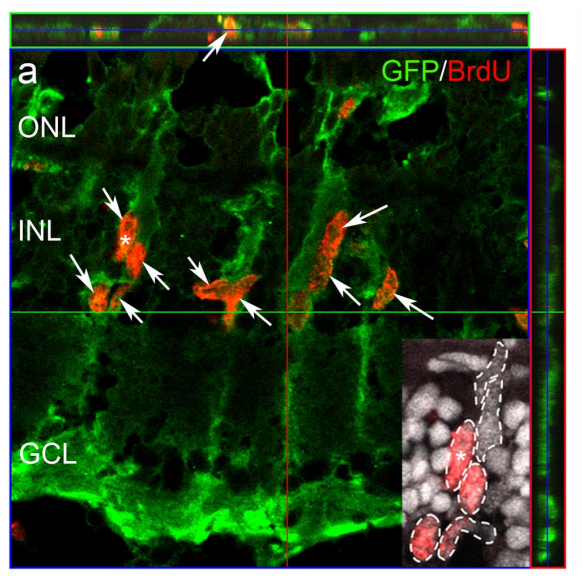
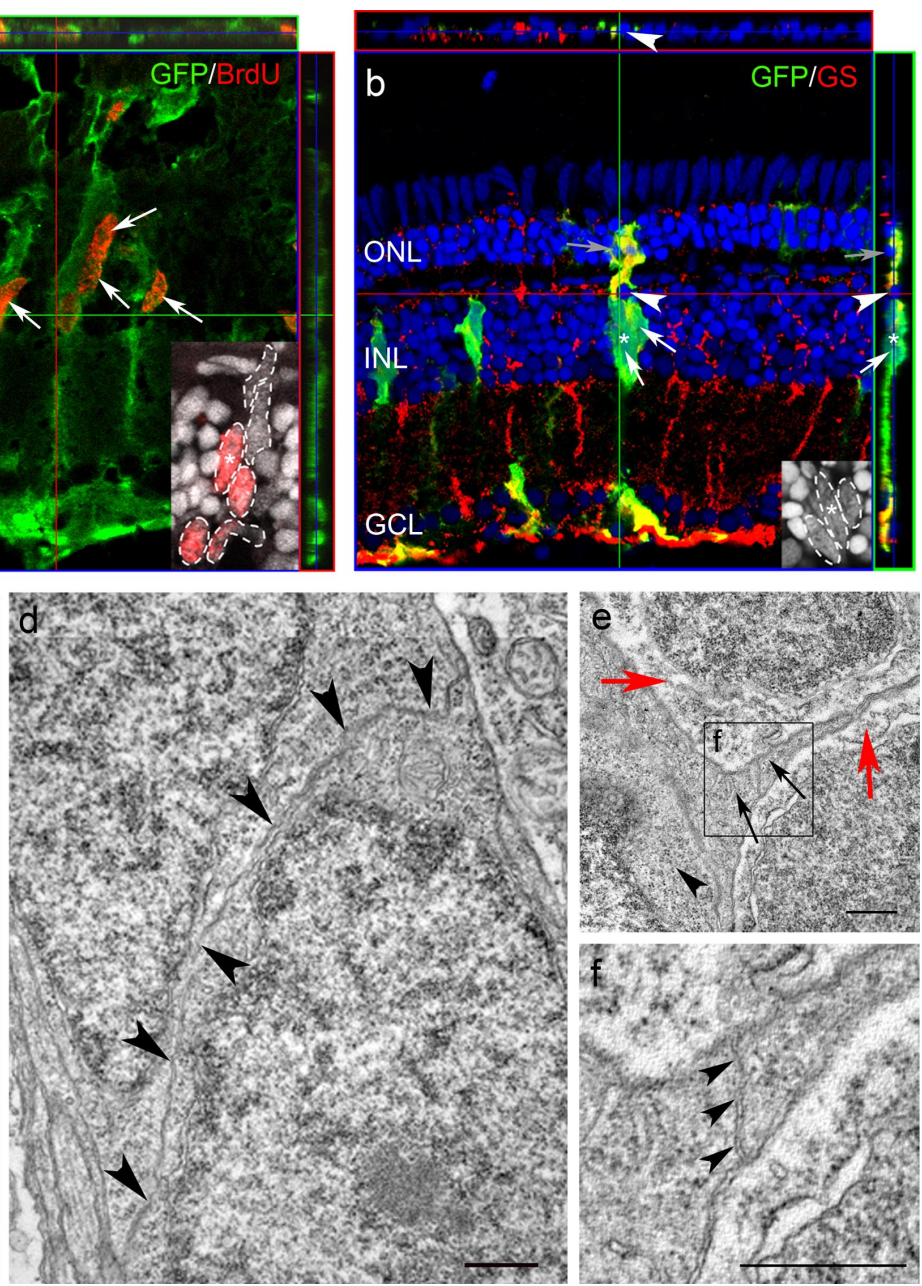

Figure 5. Neurogenic clusters are tightly apposed cells with Müller glial characteristics. $\boldsymbol{a}$, Sections from 4 dpi retina were processed for BrdU (red) and GFP (green). A stack of confocal images were obtained and used to create images in the $z$ plane (the top and right panels represent slices taken at the green and red lines, respectively). Note the multiple BrdU ${ }^{+}$nuclei within the area that corresponds to GFP ${ }^{+}$Müller glia (arrows). The inset shows a higher magnification of the BrdU ${ }^{+}$(red) nucleus marked with an asterisk in grayscale for greater clarity. Individual nuclei are outlined. $\boldsymbol{b}$, A representative image from a stack of confocal images taken from 4 dpi retina sections processed for GFP (green) and GS (red) demonstrating multiple nuclei within the area of a single Müller glia (the top and right panels represent slices taken at the red and green lines, respectively). Nuclei that are either surrounded by GFP ${ }^{+}$Müller cell processes or are within Müller glia express GFP (white arrows), whereas a nucleus that is outside the $\mathrm{GFP}^{+}$Müller glia does not (the arrowhead in each panel identifies the same nucleus). The typical glial morphology can be clearly seen in the $z$ plane (right panel, slice taken from the green line) as the cell extends from the ONL to the GCL and contacts the vitreous. A nucleus that appears to be within the Müller cell when viewed in the $x-y$ plane (gray arrow, main panel) is clearly not within the Müller cell when viewed in the $z$ plane (gray arrow, right panel) and does not express GFP. The inset shows a higher magnification of the nucleus marked with an asterisk. $\mathbf{c}-\boldsymbol{f}$, Transmission electron micrographs of a neurogenic cluster at $4 \mathrm{dpi}$. $\boldsymbol{c}$, Two nuclei with elongated morphology typical of proliferating neurogenic clusters (asterisks) near the inner plexiform layer. The boxes represent the areas shown at higher magnification in $\boldsymbol{d}$ and $\boldsymbol{e}$. Scale bar, $3 \mu \mathrm{m}$. $\boldsymbol{d}$, Composite image from two highmagnification micrographs of the cells shown in c demonstrating that these cells are separated by plasma membrane (arrowheads). Scale bar, $500 \mathrm{~nm}$. $\boldsymbol{e}$, Higher magnification of the area outlined in c. The cytoplasm of the Müller glia (black arrows; see $\boldsymbol{f}$ ) is very similar to the cytoplasm of the cells with elongated nuclei (arrowhead), whereas the cytoplasm of other cells is very different (red arrows). The box represents the area shown in $\boldsymbol{f}$. Scale bar, $500 \mathrm{~nm}$. $\boldsymbol{f}$, High magnification of the area shown in $\boldsymbol{e}$ demonstrating a junction between Müller glia (arrowheads), indicating that the elongated cells shown in c are surrounded by Müller processes. Scale bar, $500 \mathrm{~nm}$.

which is transiently expressed by retinal ganglion cells as they differentiate and extend axons (Trevarrow et al., 1990). Consistent with the idea that $\mathrm{GFP}^{+}$Müller glia generate new retinal neurons, we found $\mathrm{GFP}^{+} / \mathrm{HuC} / \mathrm{D}^{+}$cells as early as $7 \mathrm{dpi}$ (Fig. $6 a-d)$. In addition, we identified $\mathrm{GFP}^{+} / \mathrm{zn} 5^{+}$retinal ganglion cells in the INL, IPL, and GCL at 7 and $11 \mathrm{dpi}$ (11 dpi shown in Fig. $6 e-l)$. The cells in the INL and IPL may represent differentiating RGCs that are migrating to the GCL or misplaced RGCs. 
To evaluate the fate of proliferating Müller glia at later time points, we injected fish with a single dose of BrdU at 4 dpi and assayed cell fate at 60 and $180 \mathrm{dpi}$. We chose to label dividing cells at 4 dpi because it represented the peak of cell proliferation (Fig. 2a). At this time point, 98\% of the proliferating cells in the INL can be characterized as Müller glia based on morphology and GFP expression. We observed that cells labeled with BrdU at 4 dpi expressed markers of bipolar and amacrine cells, Müller glia, and cone photoreceptors at 60 and $180 \mathrm{dpi}$ (data shown for $180 \mathrm{dpi}$ in Fig. 7). Ganglion cells lose expression of zn5 shortly after their axons reach their target in the tectum, preventing their identification at these later time points, although these cells were detected at early time points (Fig. 6). We also detected $\mathrm{BrdU}^{+}$cells in the correct laminar position for horizontal cells (data not shown), although a marker specific for this cell type is not available for the zebrafish. These data indicate that cells labeled with BrdU at $4 \mathrm{dpi}$ are able to produce new neurons and glia. Similar results were obtained when BrdU was administered at $2 \mathrm{dpi}$ and cell fate was assayed at 180 dpi (data not shown). The fact that new neurons were generated is not surprising, because the capacity to regenerate after injury has been well documented; however, our data strongly suggest that these new neurons were derived from $\alpha 1$ T-expressing Müller glia.

Although nearly all of the $\mathrm{BrdU}^{+}$ cells at 4 dpi are Müller glia (see above), we wondered whether it was plausible that the few $\mathrm{BrdU}^{+} / \mathrm{GFP}^{-}$cells in the INL that were labeled at 4 dpi could give rise to all of the $\mathrm{BrdU}^{+}$cells we observe at $180 \mathrm{dpi}$. We performed a pulse-chase experiment by labeling with BrdU at 4 dpi and examining serial sections from retinas at $4,7,11$, and $180 \mathrm{dpi}$. We counted the number of $\mathrm{BrdU}^{+}$cells in

Figure 6. Cells derived from GFP ${ }^{+}$Müller glia express markers for differentiating amacrine and retinal ganglion cells. 1016 transgenic fish were injured at day 0 and allowed to recover until 7 or $11 \mathrm{dpi}$ (HuC/D shown at $7 \mathrm{dpi}$ and zn 5 at $11 \mathrm{dpi}$ ). Sections were stained for HuC/D or zn5 (red), markers for differentiating amacrine and retinal ganglion cells, respectively, and GFP (green) to detect whether GFP ${ }^{+}$cells derived from Müller glia begin to differentiate. DAPI is shown in purple to indicate the laminar position of the labeled cells. $\boldsymbol{a}-\boldsymbol{d}$, Some GFP ${ }^{+}$cells begin to express HuC/D at $7 \mathrm{dpi}$ (arrows). $\boldsymbol{e}-\boldsymbol{h}$, zn5-labeled cells in the IPL and GCL express GFP (arrows). $\boldsymbol{i}, \mathrm{A} \mathrm{GFP}^{+}$Müller-like cell with a thin axon-like projection (arrowheads). $\boldsymbol{j}$, A zn5-labeled cell extending an axon (arrowheads) into the IPL. $\boldsymbol{k}$, The $\mathrm{zn} 5^{+}$cell also expresses GFP (arrow). $I$, The newly born ganglion cell sits at the edge of the INL.

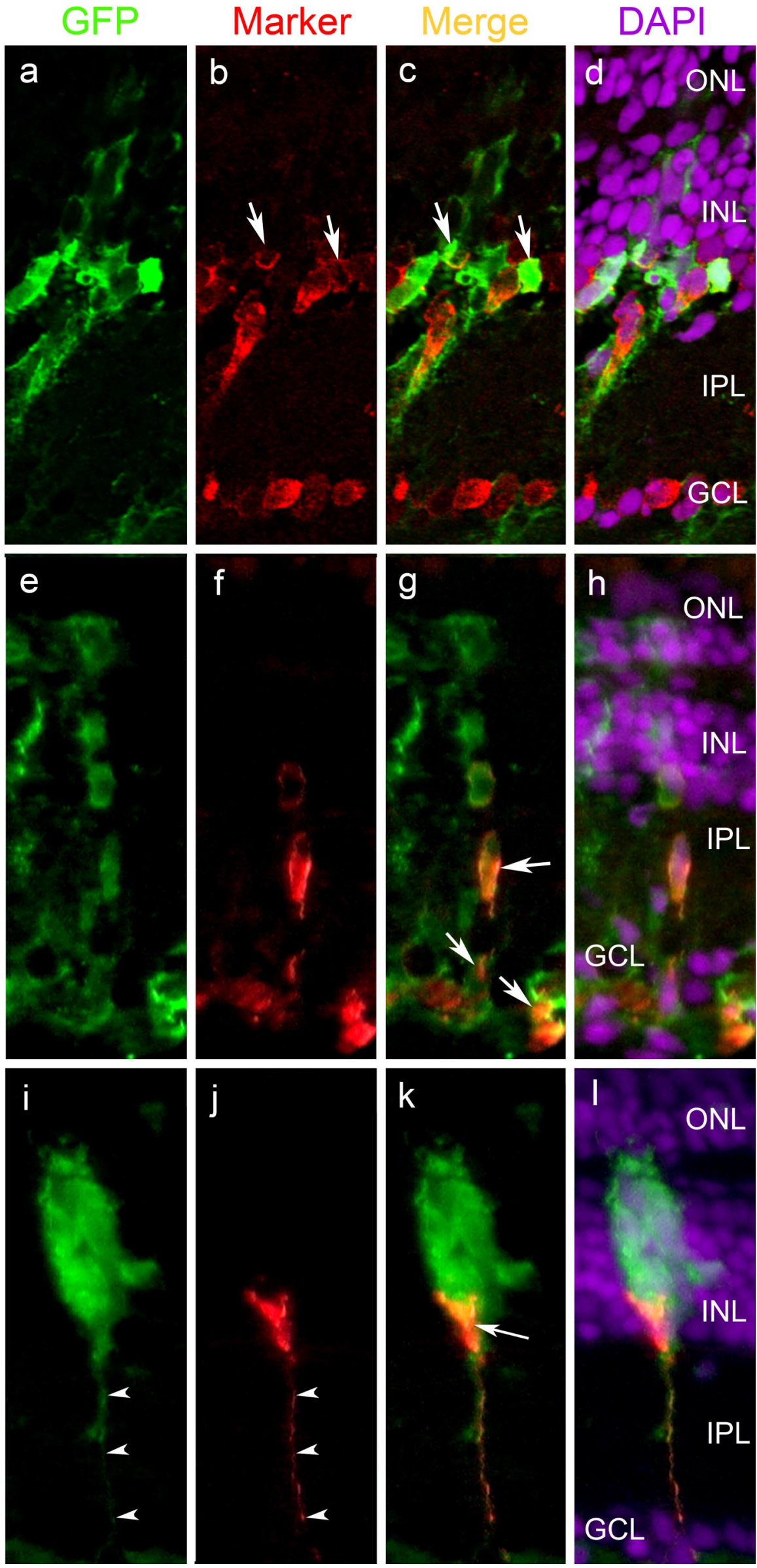



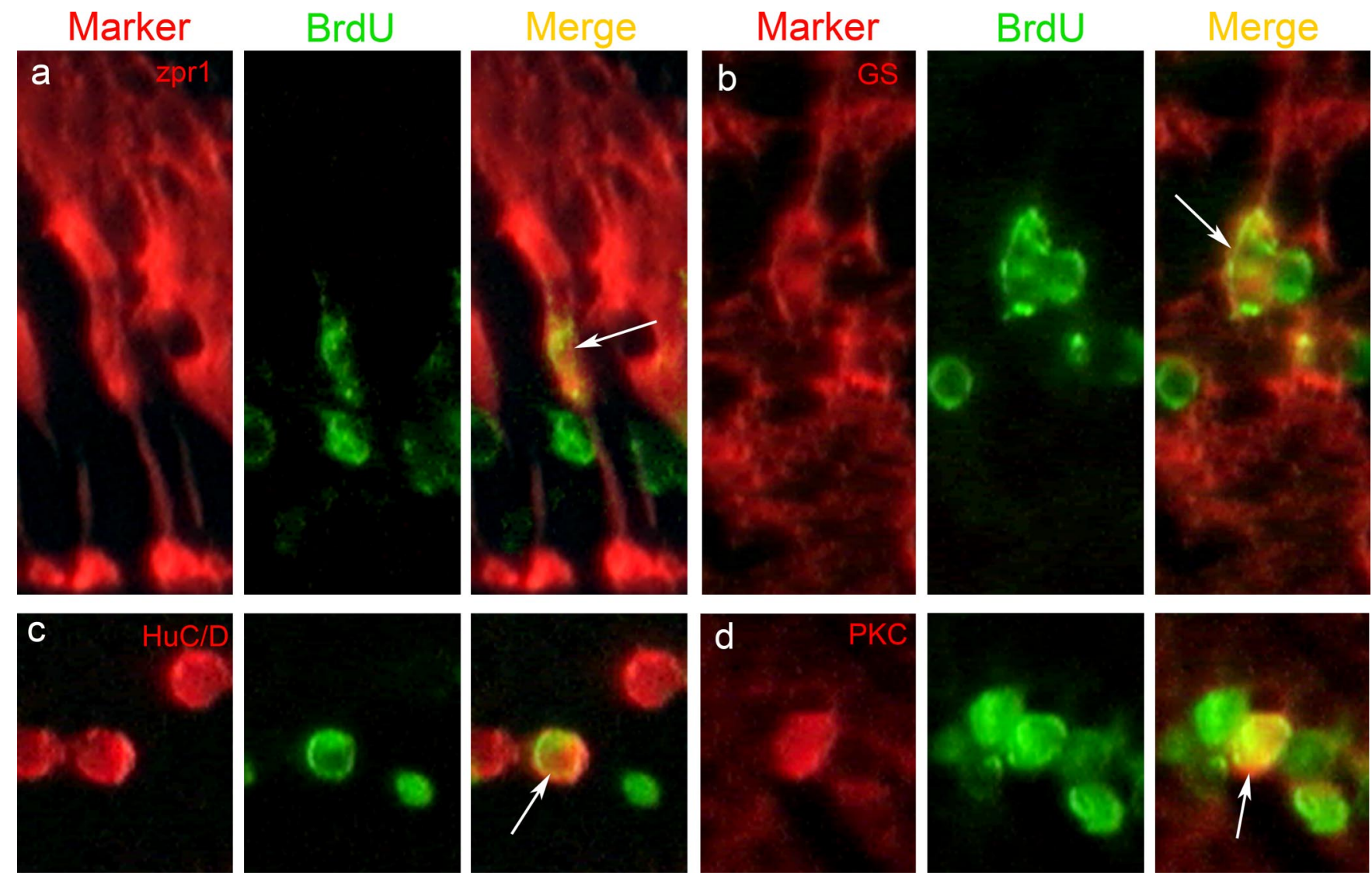

Figure 7. Cells labeled with BrdU at $4 \mathrm{dpi}$ become new neurons and glia. Fish injured at day 0 received a single injection of BrdU at $4 \mathrm{dpi}$ and were allowed to recover for $180 \mathrm{~d}$. Sections from these retinas were processed for cell-specific markers to identify retinal cell types (red) that were derived from cells labeled with BrdU (green) at 4 dpi. $\boldsymbol{a}$, BrdU ${ }^{+}$cells become cone photoreceptors after injury as indicated by a BrdU-labeled nucleus within a zpr $1^{+}$cell (arrow). $\boldsymbol{b}$, An example of a BrdU ${ }^{+} / \mathrm{GS}^{+}$Müller glia at $180 \mathrm{dpi}$ (arrow). c, A HuC/D ${ }^{+}$amacrine cell derived from a cell labeled with BrdU at 4 dpi (arrow).d, A PKC ${ }^{+}$bipolar cell derived from a cell labeled at 4 dpi (arrow). Marker, Cell-specific marker.

each nuclear layer and calculated the total number of $\mathrm{BrdU}^{+}$ cells per lesion by multiplying the average number of $\mathrm{BrdU}^{+}$ cells per lesion by the number of slides collected (we examined four lesions for 4 and 11 dpi and three lesions for 7 and 180 dpi; we collected five slides of serial sections for 4,7 , and 11 dpi and six slides for 180 dpi) (Fig. 8). Consistent with our observation that the peak of proliferation occurs at $4 \mathrm{dpi}$, we did not detect an increased number of $\mathrm{BrdU}^{+}$cells at 7, 11, or $180 \mathrm{dpi}$, indicating that the cells labeled with BrdU at 4 dpi did not undergo any significant cell division. Therefore, it is unlikely the few $\mathrm{BrdU}^{+} / \mathrm{GFP}^{-}$cells that are present at 4 dpi could be responsible for producing all of the $\mathrm{BrdU}^{+}$cells at $180 \mathrm{dpi}$.

We expected to see a change in the distribution of BrdUlabeled cells over time based on the 2 dpi pulse-chase experiments (supplemental Fig. 3, available at www.jneurosci.org as supplemental material). As expected, there is an increase in the number of $\mathrm{BrdU}^{+}$cells in the GCL at $7 \mathrm{dpi}$ and a concomitant decrease in the number of $\mathrm{BrdU}^{+}$cells in the INL (Fig. 8), suggesting that cells had migrated. We observed a gradual decrease in the number of $\mathrm{BrdU}^{+}$cells over time, suggesting that some of these cells did not persist within the retina. This decrease is most striking in the GCL, in which there are an estimated $167 \mathrm{BrdU}^{+}$cells per lesion at $7 \mathrm{dpi}$, which declines to $57 \mathrm{BrdU}^{+}$cells per lesion at $180 \mathrm{dpi}$. This decrease in cells in the GCL suggests that retinal cell death that occurs during development (Cole and Ross, 2001) may also occur as the regenerating retina matures.

\section{Discussion}

Müller glia generate new neurons and glia after retinal injury Identification of the cells responsible for regenerating the injured fish retina has eluded investigators for decades. Although some studies implicate putative INL resident stem cells (Braisted et al., 1994; Otteson et al., 2001; Wu et al., 2001), Müller glia remained as potential injury-induced progenitors. Additional support of this idea comes from recent studies demonstrating that Müller glia are able to generate neurons in the injured bird and mammalian retina (Fischer and Reh, 2001; Ooto et al., 2004). Studies designed to directly investigate whether Müller glia give rise to new neurons after retinal injury in zebrafish were not possible until now.

We provide several lines of evidence that are consistent with the hypothesis that Müller glia are a source of retina regeneration in the zebrafish. First, nearly all cells that divide in response to injury are Müller glia. We arrived at this conclusion based on evidence that most BrdU-labeled cells (94\% at $4 \mathrm{dpi}$ ) express the $1016 \alpha 1 \mathrm{~T}$ :GFP transgene and that nearly all GFP ${ }^{+}$cells (98\%) express Müller glial markers. Second, $\alpha 1 \mathrm{~T}$-expressing Müller glia give rise to neurogenic clusters (Figs. 4,5 ) that are thought to be responsible for generating new neurons in response to injury (Raymond et al., 1988). Third, $\alpha 1 \mathrm{~T}$-expressing Müller glia express genes considered to be markers of retinal stem cells such as Pax6 and $\alpha 1 \mathrm{~T}$ (Fig. 4). Fourth, recently dividing $\mathrm{GFP}^{+}$cells derived from Müller glia 
migrate to other nuclear layers (Fig. 8) (supplemental Fig. 3, available at www.jneurosci.org as supplemental material), demonstrating the capacity to replenish neurons in all layers of the retina. Fifth, $\mathrm{GFP}^{+}$cells derived from Müller glia begin expressing differentiated cell markers such as zn5, a marker for newborn retinal ganglion cells, and $\mathrm{HuC} / \mathrm{D}$ (Fig. 6). In addition, cells that are labeled with BrdU at 4 dpi ultimately generate photoreceptor, bipolar, amacrine, and Müller cells (Fig. 7 ), demonstrating the multipotency of the $\mathrm{BrdU}^{+}$cells. Last, $76 \%$ of the cells labeled with BrdU at 2 dpi are located within the INL, suggesting that the $\mathrm{BrdU}^{+}$cells found at $180 \mathrm{dpi}$ were derived from cells in the INL, where Müller cell bodies are located. When taken together, these data strongly suggest that Müller glia are a major source of retina regeneration in the zebrafish.

Although we did not observe a significant population of $\mathrm{BrdU}^{+}$cells other than Müller glia, we do not exclude the possibility that, in addition to Müller glia, putative stem cells in the INL and rod progenitors in the ONL also contribute to regeneration. However, by performing a few simple calculations based on the average number of $\mathrm{BrdU}^{+}$cells per lesion present at $4 \mathrm{dpi}$, we conclude that it is unlikely that all of the $\mathrm{BrdU}^{+}$cells observed at $180 \mathrm{dpi}$ were derived from the putative $\mathrm{BrdU}^{+} / \mathrm{GFP}^{-}$stem cells in the INL. We estimate that there are $14 \mathrm{BrdU}^{+} / \mathrm{GFP}^{-}$cells per lesion in the INL at $4 \mathrm{dpi}$ by multiplying the average number of $\mathrm{BrdU}^{+} / \mathrm{GFP}^{-}$cells observed in the INL at 4 dpi by the percentage of $\mathrm{GFP}^{-}$cells at the same time point $\left(841 \mathrm{BrdU}^{+}\right.$cells/lesion $\times 1.6 \%$ of cells that are $\left.\mathrm{GFP}^{-}=14\right)$. If these 14 cells were responsible for producing the estimated $550 \mathrm{BrdU}^{+}$cells per lesion we observe at $180 \mathrm{dpi}$, they must undergo at least five rounds of cell division between 4 and $180 \mathrm{dpi}$. Although there is more than ample time for five cell divisions between 4 and $180 \mathrm{dpi}$, we conclude it is unlikely for two reasons. First, we do not detect an increase in the number of BrdU-labeled cells over time (Fig. 8 ), and second, five rounds of cell division would likely dilute the BrdU to undetectable levels. These data suggest that cells labeled with BrdU at 4 dpi do not undergo any significant cell division at later time points. An alternative explanation is that the generation of $\mathrm{BrdU}^{+}$cells is countered by cell death. However, because apoptosis is not observed to occur in Müller glia after injury (Yurco and Cameron, 2005) and the number of proliferating cells is declining rapidly between 4 and $7 \mathrm{dpi}$, it appears that BrdU-labeled cells exhibit very little cell division after 4 dpi.

\section{Interkinetic nuclear migration as a mechanism to distribute newly born cells}

In the developing mammalian cortex, radial glia produce new neurons that inherit a cellular process that connects the newly born cell to the pial surface of the brain (Noctor et al., 2001). The newly born cell nucleus translocates from its origin through the cell process to its destination. This pattern of neurogenesis produces radial columns of clonal cells that form a functional unit in the adult cortex. During fish retina embryogenesis, a similar process occurs in which each daughter cell of a division maintains a portion of a basal process that spans the developing retina (Das et al., 2003). The basal process provides a conduit for the newly born nucleus to move through, allowing the cell body to travel without extending new connections to the basal retina. Three observations suggest that a similar mechanism may be operating in the regenerating zebrafish retina. First, nuclei from proliferating $\alpha 1 \mathrm{~T}$ -

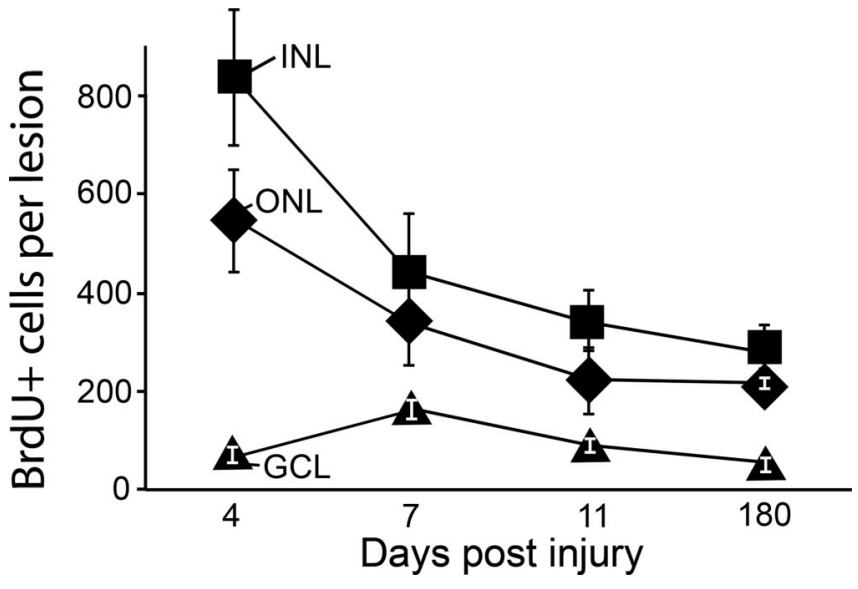

Figure 8. Cells labeled with BrdU at 4 dpi exhibit little proliferation at later times. Fish injured at day 0 were given a single dose of BrdU at 4 dpi and killed at 4, 7, 11, or $180 \mathrm{dpi}$. Serial sections were collected and processed for BrdU labeling to follow the cells labeled at $4 \mathrm{dpi}$. The average number of BrdU-labeled cells per lesion is shown for each time point examined. The number of BrdU ${ }^{+}$cells in the ONL and INL declines over time, whereas the number of labeled cells in the GCL increases at $7 \mathrm{dpi}$, suggesting that cells had migrated there. The lack of an increase in the overall number of BrdU-labeled cells over time suggests that cells labeled with BrdU at 4 dpi generally do not continue to progress through the cell cycle. In fact, there is a decline in the total number of cells, suggesting that some of the labeled cells had undergone apoptosis.

expressing Müller glia are observed to migrate from the INL to other nuclear layers in response to injury (Fig. 8) (supplemental Figs. 3, 4, available at www.jneurosci.org as supplemental material) (Braisted et al., 1994; Wu et al., 2001; Yurco and Cameron, 2005). Second, $\mathrm{GFP}^{+} / \mathrm{zn} 5^{+}$cell bodies derived from Müller glia appear to be migrating to the GCL to become new retinal ganglion cells (Fig. 6). Third, newly born cells appear to migrate along Müller processes to reach their destination (Vihtelic and Hyde, 2000). Based on these observations, we propose that newly regenerated cells retain a portion of the parental Müller glial process that spans the retina. Nuclear migration in these cells would therefore be similar to the interkinetic nuclear movement observed during mammalian cortex and zebrafish retina development, namely that the new nucleus simply migrates through its cytoplasmic connection to the appropriate nuclear layer, and the cellular process is retracted or used in the formation of an axon.

\section{$1016 \alpha 1$ TGFP expression as a reporter for an} injury-induced signal

We noticed that there appeared to be a higher percentage of Müller glia that expressed GFP near the injury site when compared with GFP-expressing Müller glia distal to the lesion. The percentage of GFP-expressing Müller glia goes from upwards of $90 \%$ near the lesion to $0 \%$ at sites distal to the lesion (data not shown). This observation is consistent with previous work demonstrating a direct correlation between distance from the injury site and the number of proliferating cells (Yurco and Cameron, 2005) and that there is more $\alpha 1$ T transgene expression in the portion of the retina that receives the most damage (Vihtelic et al., 2006). These data suggest that Müller glia may respond to an injury-induced signal emanating from the injury site and that this signal may be involved in the activation of $\alpha 1 \mathrm{~T}$ gene expression. Although the signals initiating retinal regeneration are not known, they may emanate from photoreceptors because they must be damaged to initiate a regener- 
ative response (Braisted and Raymond, 1992; Braisted et al., 1994). In the mouse, there is evidence that photoreceptors signal damage to Müller glia through endothelin receptor (Rattner and Nathans, 2005). It will be interesting to investigate whether endothelin signaling is involved in regulating the response of Müller glia to retinal injury.

\section{Implications for regeneration in mammals}

It is interesting to note that Müller glia from a variety of organisms begin to proliferate in response to injury and induce expression of filamentous proteins such as GFAP (Grosche et al., 1995; Sarthy and Egal, 1995; McGillem and Dacheux, 1999), $\alpha 1$ T (Senut et al., 2004; Vihtelic et al., 2006), neurofilament (Fischer and Reh, 2001), and vimentin (Lewis and Fisher, 2003). The induction of a group of architectural proteins across species suggests that an evolutionarily conserved mechanism may be acting to induce Müller glia to proliferate in all of these species. In humans, Müller glial proliferation is known as reactive gliosis, which could be an attempt to limit retinal damage and is often associated with pathology (Bringmann and Reichenbach, 2001). Gliosis may occur in an attempt to clear neuronal debris (Pearson et al., 1993) but, in fish, Müller glia do not phagocytose in vivo (Wagner and Raymond, 1991), suggesting that these cells may play a different role in teleosts. Our data suggest that Müller glia in zebrafish play a role in regeneration of the damaged retina, and, although retina regeneration in birds and mammals is limited compared with fish, the common use of Müller glia as a retinal progenitor suggests that a similar mechanism may be acting to produce new neurons in all of these species. Zebrafish represent an ideal system to unravel the mechanisms of retina regeneration because of their robust regenerative response and amenability to molecular studies. In contrast, regeneration in the chick retina is meager and restricted to the postnatal period. Regeneration in the mammalian retina is even poorer. Nonetheless, it is interesting that the limited amount of regeneration observed in the mammalian retina can be attributed to Müller glia (Ooto et al., 2004). Thus, it is likely that studies of fish retina regeneration will reveal mechanisms that are also relevant to repair of the damaged mammalian retina.

\section{References}

Barthel LK, Raymond PA (2000) In situ hybridization studies of retinal neurons. Methods Enzymol 316:579-590.

Bormann P, Zumsteg VM, Roth LW, Reinhard E (1998) Target contact regulates GAP-43 and alpha-tubulin mRNA levels in regenerating retinal ganglion cells. J Neurosci Res 52:405-419.

Braisted JE, Raymond PA (1992) Regeneration of dopaminergic neurons in goldfish retina. Development 114:913-919.

Braisted JE, Essman TF, Raymond PA (1994) Selective regeneration of photoreceptors in goldfish retina. Development 120:2409-2419.

Bringmann A, Reichenbach A (2001) Role of müller cells in retinal degenerations. Front Biosci 6:E72-E92.

Byrd CA, Brunjes PC (2001) Neurogenesis in the olfactory bulb of adult zebrafish. Neuroscience 105:793-801.

Cameron DA (2000) Cellular proliferation and neurogenesis in the injured retina of adult zebrafish. Vis Neurosci 17:789-797.

Cole LK, Ross LS (2001) Apoptosis in the developing zebrafish embryo. Dev Biol 240:123-142.

Das T, Payer B, Cayouette M, Harris WA (2003) In vivo time-lapse imaging of cell divisions during neurogenesis in the developing zebrafish retina. Neuron 37:597-609.

Faillace MP, Julian D, Korenbrot JI (2002) Mitotic activation of proliferative cells in the inner nuclear layer of the mature fish retina: regulatory signals and molecular markers. J Comp Neurol 451:127-141.

Fischer AJ, Reh TA (2001) Müller glia are a potential source of neural regeneration in the postnatal chicken retina. Nat Neurosci 4: $247-252$.

Goldman D, Ding J (2000) Different regulatory elements are necessary for alpha1 tubulin induction during CNS development and regeneration. NeuroReport 11:3859-3863.

Goldman D, Hankin M, Li Z, Dai X, Ding J (2001) Transgenic zebrafish for studying nervous system development and regeneration. Transgenic Res 10:21-33.

Grosche J, Hartig W, Reichenbach A (1995) Expression of glial fibrillary acidic protein (GFAP), glutamine synthetase (GS), and bcl-2 protooncogene protein by müller (glial) cells in retinal light damage of rats. Neurosci Lett 185:119-122.

Hieber V, Dai X, Foreman M, Goldman D (1998) Induction of alpha1tubulin gene expression during development and regeneration of the fish central nervous system. J Neurobiol 37:429-440.

Hitchcock P, Ochocinska M, Sieh A, Otteson D (2004) Persistent and injury-induced neurogenesis in the vertebrate retina. Prog Retin Eye Res 23:183-194.

Hitchcock PF, Lindsey Myhr KJ, Easter Jr SS, Mangione-Smith R, Jones DD (1992) Local regeneration in the retina of the goldfish. J Neurobiol 23:187-203.

Hitchcock PF, Macdonald RE, VanDeRyt JT, Wilson SW (1996) Antibodies against Pax6 immunostain amacrine and ganglion cells and neuronal progenitors, but not rod precursors, in the normal and regenerating retina of the goldfish. J Neurobiol 29:399-413.

Johns PR (1977) Growth of the adult goldfish eye. III. Source of the new retinal cells. J Comp Neurol 176:343-357.

Krebs W, Krebs I (1991) Primate retina and choroid: atlas of its fine structure in man and monkey. New York: Springer.

Larison KD, Bremiller R (1990) Early onset of phenotype and cell patterning in the embryonic zebrafish retina. Development 109:567-576.

Levine EM, Hitchcock PF, Glasgow E, Schechter N (1994) Restricted expression of a new paired-class homeobox gene in normal and regenerating adult goldfish retina. J Comp Neurol 348:596-606.

Lewis GP, Fisher SK (2003) Up-regulation of glial fibrillary acidic protein in response to retinal injury: its potential role in glial remodeling and a comparison to vimentin expression. Int Rev Cytol 230:263-290.

Maier W, Wolburg H (1979) Regeneration of the goldfish retina after exposure to different doses of ouabain. Cell Tissue Res 202:99-118.

McGillem GS, Dacheux RF (1999) Rabbit retinal müller cells undergo antigenic changes in response to experimentally induced proliferative vitreoretinopathy. Exp Eye Res 68:617-627.

Meyer RL (1978) Evidence from thymidine labeling for continuing growth of retina and tectum in juvenile goldfish. Exp Neurol 59:99-111.

Negishi K, Shinagawa S (1993) Fibroblast growth factor induces proliferating cell nuclear antigen-immunoreactive cells in goldfish retina. Neurosci Res 18:143-156.

Noctor SC, Flint AC, Weissman TA, Dammerman RS, Kriegstein AR (2001) Neurons derived from radial glial cells establish radial units in neocortex. Nature 409:714-720.

Ooto S, Akagi T, Kageyama R, Akita J, Mandai M, Honda Y, Takahashi M (2004) Potential for neural regeneration after neurotoxic injury in the adult mammalian retina. Proc Natl Acad Sci USA 101:13654-13659.

Otteson DC, D'Costa AR, Hitchcock PF (2001) Putative stem cells and the lineage of rod photoreceptors in the mature retina of the goldfish. Dev Biol 232:62-76.

Pearson HE, Payne BR, Cunningham TJ (1993) Microglial invasion and activation in response to naturally occurring neuronal degeneration in the ganglion cell layer of the postnatal cat retina. Brain Res Dev Brain Res 76:249-255.

Perry GW, Burmeister DW, Grafstein B (1987) Fast axonally transported proteins in regenerating goldfish optic axons. J Neurosci 7:792-806.

Rattner A, Nathans J (2005) The genomic response to retinal disease and injury: evidence for endothelin signaling from photoreceptors to glia. J Neurosci 25:4540-4549.

Raymond PA, Reifler MJ, Rivlin PK (1988) Regeneration of goldfish retina: rod precursors are a likely source of regenerated cells. J Neurobiol 19:431-463.

Sarthy V, Egal H (1995) Transient induction of the glial intermediate fila- 
ment protein gene in müller cells in the mouse retina. DNA Cell Biol 14:313-320

Senut M, Gulati-Leekha A, Goldman D (2004) An element in the $\alpha 1$ tubulin promoter is necessary for retinal expression during optic nerve regeneration but not after eye injury in the adult zebrafish. J Neurosci 24:7663-7673.

Sullivan SA, Barthel LK, Largent BL, Raymond PA (1997) A goldfish notch-3 homologue is expressed in neurogenic regions of embryonic, adult, and regenerating brain and retina. Dev Genet 20:208-223.

Trevarrow B, Marks DL, Kimmel CB (1990) Organization of hindbrain segments in the zebrafish embryo. Neuron 4:669-679.

Vihtelic TS, Hyde DR (2000) Light-induced rod and cone cell death and regeneration in the adult albino zebrafish (Danio rerio) retina. J Neurobiol 44:289-307.
Vihtelic TS, Soverly JE, Kassen SC, Hyde DR (2006) Retinal regional differences in photoreceptor cell death and regeneration in light-lesioned albino zebrafish. Exp Eye Res 82:558-575.

Wagner EC, Raymond PA (1991) Müller glial cells of the goldfish retina are phagocytic in vitro but not in vivo. Exp Eye Res 53:583-589.

Wu DM, Schneiderman T, Burgett J, Gokhale P, Barthel L, Raymond PA (2001) Cones regenerate from retinal stem cells sequestered in the inner nuclear layer of adult goldfish retina. Invest Ophthalmol Vis Sci 42:2115-2124.

Yazulla S, Studholme KM (2001) Neurochemical anatomy of the zebrafish retina as determined by immunocytochemistry. J Neurocytol 30:551-592.

Yurco P, Cameron DA (2005) Responses of müller glia to retinal injury in adult zebrafish. Vision Res 45:991-1002. 